\title{
On the co-movements among gold and other financial markets: a multivariate time-varying asymmetric approach
}

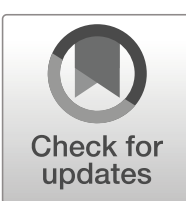

\author{
Riadh El Abed ${ }^{1} \cdot$ Amna Zardoub ${ }^{2}$
}

Published online: 6 June 2019

(C) The Author(s) 2019

\begin{abstract}
The analysis of time varying correlation between gold price and financial market in the context of international investments has been well researched in the literature in last few years. In this paper we study the interdependence of three financial markets and the gold price. We adopt a multivariate asymmetric dynamic conditional correlation EGARCH framework, during the period spanning from January 5, 1995 until May 30, 2017. The empirical results suggest asymmetric responses in correlations among gold market and financial market. We find that asymmetric dynamic correlations exhibit substantial time variation even in similar market tensions for same pairs of assets. Our findings imply that investors and fund managers should take into account the asymmetric dependence structure, which depends on the upside or downside of the market.
\end{abstract}

Keywords A-DCC model · Gold market · Exchange market · Stock market and asymmetries

JEL classification $\mathrm{C} 13 \cdot \mathrm{C} 22 \cdot \mathrm{C} 32 \cdot \mathrm{C} 52 \cdot \mathrm{C} 53 \cdot \mathrm{G} 15$

\section{Introduction}

The dynamic relationships between gold and other financial market have attracted a special attention from both practitioners and academics. A strong relationship between

Riadh El Abed

riadh.abed@gmail.com

Amna Zardoub

zardoubamna@gmail.com

1 Faculté des Sciences Economiques et de Gestion de Tunis, Laboratoire d'Ingénierie Financière et Economique (LIFE), University of Tunis El Manar, Tunis, Tunisia

2 Faculté des Sciences Economiques et de Gestion de Sousse, Laboratoire: Economie appliquée et simulation (EAS), FSEG Mahdia, University of Sousse, Sousse, Tunisia 
them would have important implications for international capital budgeting decisions and economic policies because negative shocks affecting one market may be transmitted quickly to another through contagious effects. This issue has become more critical with the occurrence of recent black swan events such as the US 2007 subprime crisis.

A common and pronounced finding presented in recent finance literature is that asset returns exhibit asymmetric dependence, that is, financial markets behaves differently between tranquil and extreme conditions. The presence of asymmetries in financial markets casts doubt on the benefit of portfolio diversification and the effectiveness of risk management.

Gold is a strategic resource that is largely used in national security and in various national economic activities. Large fluctuations in the gold market lead to increased price volatility. The latter imposes challenges on market participants such as consumers and producers and affects price stabilization policies, who often try to predict the future price of gold.

The empirical evidence on the gold - financial markets relationships has been document by numerous studies, for example, Longin and Solnik (2001) and Ang and Chen (2002) examine asymmetry in stock returns using exceedance correlation (see Ang and Bekaert (2002)). Campbell et al. (2008) reject the normality in the distribution of financial asset returns. Number of studies evaluate the function of gold as a hedge or safe haven asset (Hillier et al. 2006; Baur and Lucey 2010; Baur and McDermott 2010; Qadan and Yagil 2012; Hood and Malik 2013; Miyazaki and Hamori 2013). On the other hand, several studies show that gold has strengthened linkages with other financial assets owing to the financialization of commodities (Domanski and Heath 2007; Baur 2011; Tang and Xiong 2012; Silvennoinen and Thorp 2013; Miyazaki and Hamori 2014).

In emerging markets, which attract global institutional investors, prior studies provide evidence of significant interactions between gold and equity prices and their volatilities (e.g., Wang et al. 2010, and Arouri et al. 2015, for China; Jain and Biswal 2016, for India; Raza et al. 2016, for emerging markets; Kumar 2014). Some other studies document hedge and/or safe-haven properties of gold for stock markets (see, among others, Arouri et al. 2015, for China; Gurgun and Unalmis 2014, for emerging markets).

To examine the interaction between gold and stock market, some econometric methods are used. For example, Bekiros et al. (2017) use a GARCH-based copula methodology and a wavelet approach to studies the hedging and diversification roles of gold for BRICS stock markets. Results indicate the evidence of two-way causality linkages, suggesting that gold behaves more like equities. In the other hand, Sarwar (2017) considers the links between the implied volatilities of US stock markets and the gold, the author disregards the relationships in large emerging markets.

Recently, Sarwar and Khan (2017) use a GARCH models and the Granger causality test, and they indicates that intensified US market uncertainty reduces emerging market returns in Latin America and increases the variance of returns. Bouri et al. (2017a) find the presence of nonlinearity and significant co-integration in the interaction between the implied volatilities of gold, crude oil and Indian equities. Bouri et al. (2017b) examine the short- and long-term causality between the implied volatility of gold and that of India and China. The authors show evidence of a feedback effect. Yang and Zhou (2017) identify the significant impact of quantitative easing on the implied volatility spillovers across US Treasury bonds commodities and developed stock market indices. 
In the context of asymmetric effect and time varying, Kang et al. (2016) show that the dynamic correlations among BRICS markets and commodities (oil and gold) are time varying and sensitive to major economic and financial events. Some studies consider the effect of the global financial crisis. For example, Xu and Hamori (2012) use the cross-correlation function approach and indicate that the volatility linkages between the US and BRIC stock markets have significantly eased after the GFC. In addition, Mensi et al. (2014) use a quantile regression approach and find that the BRICS stock markets exhibit dependence on the US equities, gold markets and crude oil, and that dependence is affected by the global financial crisis (GFC).

The main objective of this work is to explore the asymmetric dynamics in the correlations among gold and other financial markets, as this remains under explored in empirical research. Furthermore, it would be interesting to conduct an empirical analysis on how the dependence structures of the gold and financial market changed particularly at the different phases of financial markets, the subprime mortgage turmoil and the global financial crisis. Two major contributions on this topic are made in the present study. First, we investigate the asymmetric behavior of dynamic correlations among gold and financial market by employing the multivariate asymmetric DCC (A-DCC) model put forward by Cappiello et al. (2006). The A-DCC model allows for conditional asymmetries in covariance and correlation dynamics, thereby enabling to examine the presence of asymmetric responses in correlations during periods of negative shocks. Second, we evaluate how the selected period of crises influenced the estimated DCCs among the currency markets.

This article is organized as follows. In the next section, we briefly review the methodology to test for asymmetry in the correlation. Section 3 describes the data and Section 4 presents our empirical results. Section 5 concludes.

\section{Econometric methodology}

To investigate the dynamics of the correlations between gold and other financial markets namely, S\&P500 index (SPX), the Bank of America Merrill Lynch U.S. Corp. Master Total Return Index (CMBI), and the trade weighted U.S. dollar index against major currencies (USDI), we use the asymmetric generalized dynamic conditional correlation (AG-DCC) model developed by Cappiello et al. (2006). This approach generalizes the DCC model of Engle (2002) by introducing two modifications: asset-specific correlation evolution parameters and conditional asymmetries in correlation dynamics. In this paper, we adopt the following three step approach (see also Kenourgios et al. (2011), Toyoshima et al. (2012), Samitas and Tsakalos (2013) and Toyoshima and Hamori (2013)). In the first step, we estimate the conditional variances of gold and financial market returns using an autoregressive- asymmetric exponential generalized autoregressive conditional heteroscedasticity $(\operatorname{AR}(m)-\operatorname{EGARCH}(p, q)) \operatorname{model}^{1}$. For a more detailed analysis, we use the following equations:

\footnotetext{
${ }^{1}$ See Nelson (1991).
} 


$$
\begin{gathered}
r_{t}=\mu_{0}+\sum_{i=1}^{m} \mu_{i} r_{t-i}+\varepsilon_{t} \\
\ln \left(h_{t}\right)=\omega+\sum_{i=1}^{q}\left[\alpha_{i}\left|z_{t-i}\right|+\gamma_{i} z_{t-i}\right]+\sum_{i=1}^{p} \beta_{i} \ln \left(h_{t-i}\right)
\end{gathered}
$$

where $r_{t}$ indicates gold returns and financial market return, $\varepsilon_{t}$ is the error term, $h_{t}$ is the conditional volatility, and $z_{t}=\varepsilon_{t} / \sqrt{h_{t}}$ is the standardized residual.

The EGARCH model has several advantages over the pure GARCH specification. First, since $\ln \left(h_{t}\right)$ is modelled, then even if the parameters are negative, $h_{t}$ will be positive. There is thus no need to artificially impose nonnegativity constraints on the model parameters. Second, asymmetries are allowed for under the EGARCH formulation, since if the relationship between volatility and returns is negative, $\gamma_{i}$ will be negative. Note that a negative value of $\gamma_{i}$ means that negative residuals tend to produce higher variances in the immediate future.

We assume that the random variable $z_{t}$ has a student distribution (see Bollerslev (1987)) with $v>2$ degrees of freedom with a density given by:

$$
D\left(z_{t}, v\right)=\frac{\Gamma\left(v+\frac{1}{2}\right)}{\Gamma\left(\frac{v}{2}\right) \sqrt{\pi(v-2)}}\left(1+\frac{z_{t}^{2}}{v-2}\right)^{\frac{1}{2}-v}
$$

Where $\Gamma(v)$ is the gamma function and $v$ is the parameter that describes the thickness of the distribution tails. The Student distribution is symmetric around zero and, for $v>4$, the conditional kurtosis equals $3(v-2) /(v-4)$, which exceeds the normal value of three. For large values of $v$, its density converges to that of the standard normal.

The log form of the $\operatorname{EGARCH}(p, q)$ model ensures the positivity of the conditional variance, without the need to constrain the parameters of the model. The term $z_{t-i}$ indicates the asymmetric effect of positive and negative shocks. If $\gamma_{i}>0$, then $z_{t-}$ ${ }_{i}=\varepsilon_{t-i} / \sigma_{t-i}$ is positive. The term $\sum_{i=1}^{p} \beta_{i}$ measures the persistence of shocks to the conditional variance.

The conditional mean equation (Eq. 1) is specified as an autoregressive process or order $m$. The optimal lag length $m$ for each asset return series is given by the Schwartz-Bayesian Information Criterion (SBIC). (Eq. 2).represents the conditional variance and is specified as and $\operatorname{EGARCH}(p, q)$ process. The optimal lag lengths $p$ and $q$ are determined by employing the SBIC criterion.

From Eq. 2, we first obtain the conditional volatilities and then recover the conditional correlations. The conditional covariance matrix is then defined as follows:

$$
H_{t}=D_{t} R_{t} D_{t}
$$

where the diagonal matrix $D_{t}$ is the conditional standard deviation obtained from Eq. 2 . The matrix of the standardized residuals $Z_{t}$ is used to estimate the parameters of the Asymmetric dynamic conditional correlation (A-DCC) model developed by Cappiello et al. (2006). The AG-DCC model is given as 


$$
Q_{t}=\left(\bar{Q}-A^{\prime} \bar{Q} A-B^{\prime} \bar{Q} B-G^{\prime} \bar{N} G\right)+A^{\prime} Z_{t-1} Z_{t-1}^{\prime} A+B^{\prime} Q_{t-1} B+G^{\prime} \eta_{t-1} \eta_{t-1}^{\prime} G
$$

where $\bar{Q}$ and $\bar{N}=E\left(\eta_{t} \eta_{t}^{\prime}\right)$ are the unconditional correlation matrices of $Z_{t}$ and $\eta_{t} \cdot \eta_{t}=$ $I\left[Z_{t}<0\right] \cdot Z_{t} . I[$.$] is an indicator function such that I=1$ if $Z_{t}<0$ and $I=0$ if $Z_{t} \geq 0$, while $" \circ "$ is the Hadamard product.

The A-DCC $(1,1)$ model is identified as a special case of the AG-DCC $(1,1)$ model if the matrices $A, B$ and $G$ are replaced by the scalars $a_{1}, b_{1}$ and $g_{1}$. Cappiello et al. (2006) show that $Q_{t}$ is positive definite with a probability of one if $\left(\bar{Q}-A^{\prime} \bar{Q} A-B^{\prime} \bar{Q} B-G^{\prime} \bar{N} G\right)$ is positive definite. The next step consists in computing the correlation matrix $R_{t}$ from the following equation:

$$
R_{t}=Q_{t}^{*-1} Q_{t} Q_{t}^{*-1}
$$

Where $Q_{t}^{*}=\sqrt{q_{i i, t}}$ is a diagonal matrix with a square root of the $i t h$ diagonal element of $Q_{t}$ on its ith diagonal position.

\section{Data description}

The data comprises daily gold PM fixing (Gold) released by the London Bullion Market Association and the S\&P500 index (SPX), the Bank of America Merrill Lynch U.S. Corp. Master Total Return Index (CMBI), and the trade weighted U.S. dollar index against major currencies (USDI), respectively. For each currency, the continuously compounded return is computed as: $r_{t}=100 * \ln \left(\frac{p_{t}}{p_{t-1}}\right)$ for $t=1,2, \ldots T$, where $p_{t}$ is the price on day $t$. The sample covers a period from January 05, 1995 until May 30, 2017, leading to a sample size of 8213 observations. SPX is from DataStream. CMBI and USDI are from the Federal Reserve Economic Database of the St. Louis FED.

To examine the time variation of correlation dynamics, we split the sample into three subsample periods: the first period is 5 January 1995-10 September 2001; the second is 11 September 2001-August 7, 2007; and the third is 8 August 2007-30 May 2017. Each subsample is characterized by different phases of financial markets and virtually corresponds to the moderation era until the collapse of the dot-com bubble and terrorist attacks (subsample 1); the asset price, especially housing, boom era until the subprime mortgage turmoil (subsample 2); and the global financial crisis era to present (subsample 3).

Table 1 reports the descriptive statistics for our data set per subsample period. In the whole sample and the subsample one, the SPX exhibits the largest positive mean return, thereby suggesting that the stock price is most significantly. In addition, the standard deviation or volatility of SPX is the highest over the sample period. The higher levels of Skewness for each return series indicate that extreme variations tend to occur more frequently for these currencies. Besides, there exist fat tails in the return distribution according to the high values of kurtosis for all returns. To accommodate the existence of "fat tails", we assume student-t distributed innovations. Furthermore, the JarqueBera statistic rejects normality assumption at the $1 \%$ level for all for all gold and financial markets. 


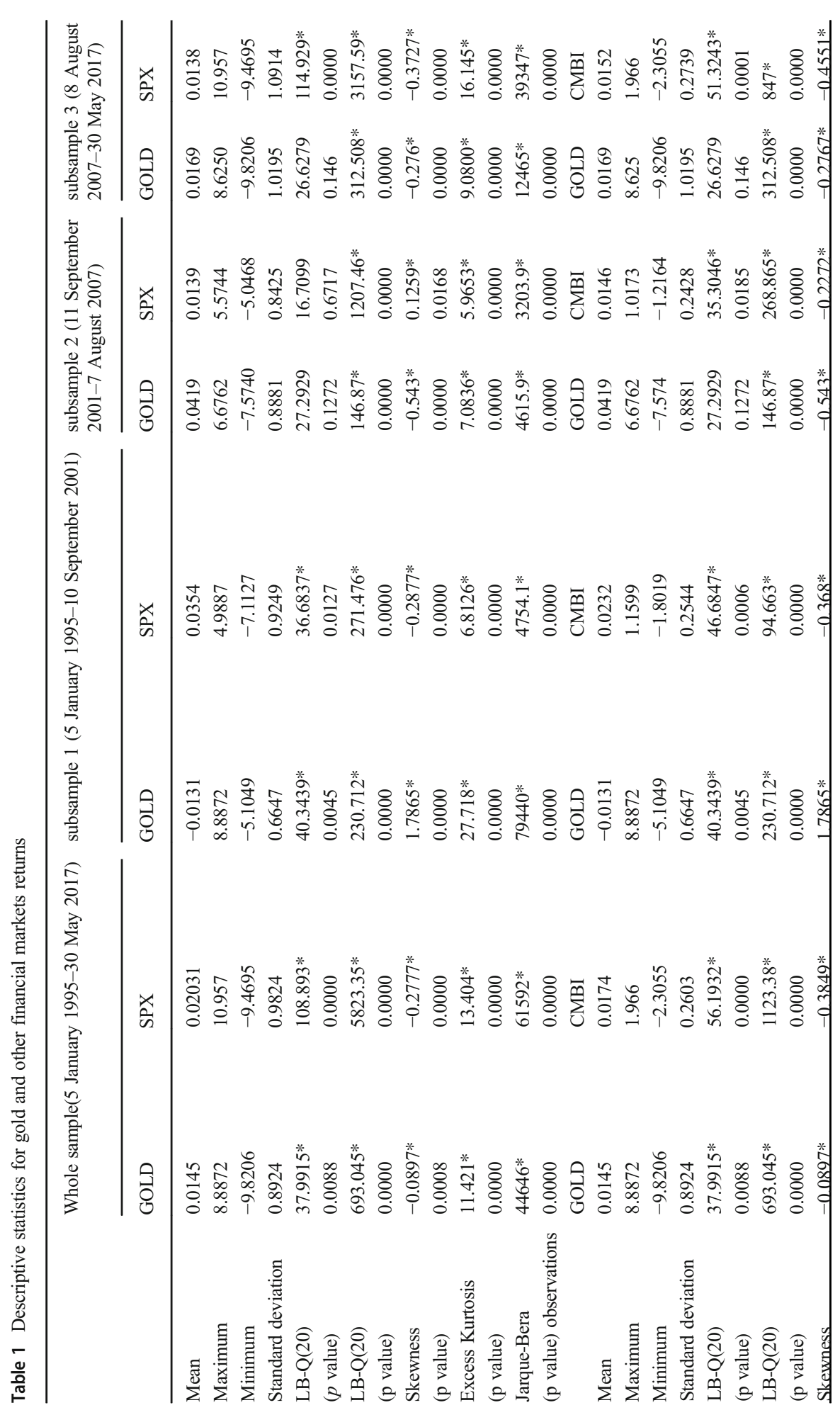




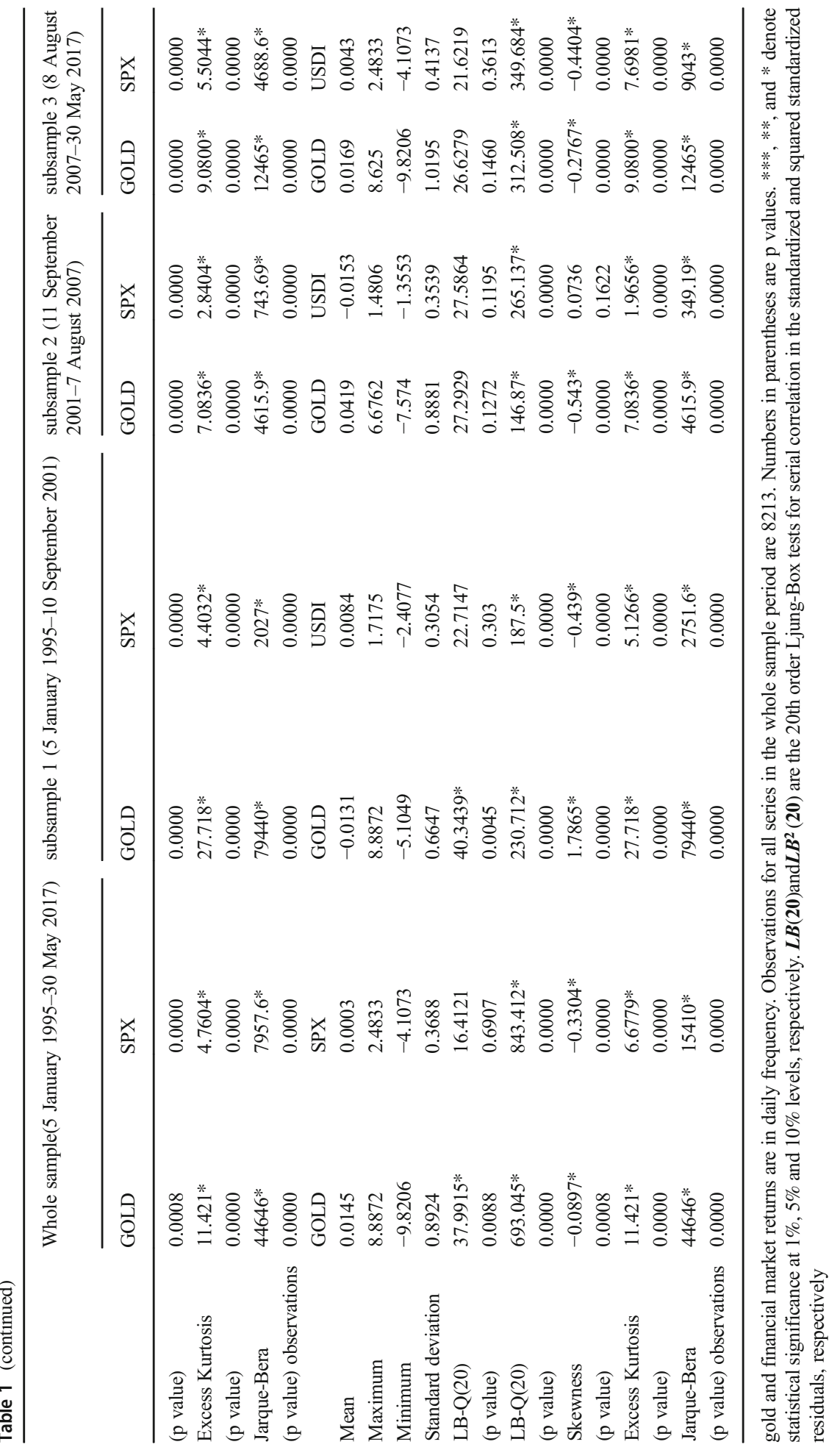


The gold exhibits the largest positive mean return in subsample two, thereby suggesting that the gold return is most significantly. In addition, the standard deviation or volatility of gold is the highest over the subsample two. The higher levels of Skewness for each return series indicate that extreme variations tend to occur more frequently for these currencies. Besides, there exist fat tails in the return distribution according to the high values of kurtosis for gold and stock returns. To accommodate the existence of "fat tails", we assume student-t distributed innovations. Furthermore, the Jarque-Bera statistic rejects normality assumption at the $1 \%$ level for all for all gold and financial markets.

In subsample 3, gold exhibits the largest positive mean return in subsample three; thereby suggesting that the gold return is most significantly. In addition, the standard deviation or volatility of stock return (SPX) is the highest over the subsample three. The higher levels of Skewness for each return series indicate that extreme variations tend to occur more frequently for these currencies. Besides, there exist fat tails in the return distribution according to the high values of kurtosis for stock returns. To accommodate the existence of "fat tails", we assume student-t distributed innovations. Furthermore, the Jarque-Bera statistic rejects normality assumption at the $1 \%$ level for all for all gold and financial markets.

\section{Tests for sign and size bias}

Engle and Ng (1993) propose a set of tests for asymmetry in volatility, known as sign and size bias tests. The Engle and $\mathrm{Ng}$ tests should thus be used to determine whether an asymmetric model is required for a given series, or whether the symmetric GARCH model can be deemed adequate. In practice, the Engle-Ng tests are usually applied to the residuals of a GARCH fit to the returns data.

Define $S_{t-1}^{-}$as an indicator dummy variable such as:

$$
S_{t-1}^{-}=\left\{\begin{array}{rr}
1 & \text { if } \hat{z}_{t-1}<0 \\
0 & \text { otherwise }
\end{array}\right.
$$

The test for sign bias is based on the significance or otherwise of $\phi_{1}$ in the following regression:

$$
\hat{z}_{t}^{2}=\phi_{0}+\phi_{1} S_{t-1}^{-}+\nu_{t}
$$

where $\nu_{t}$ is an independent and identically distributed error term. If positive and negative shocks to $\hat{z}_{t-1}$ impact differently upon the conditional variance, then $\phi_{1}$ will be statistically significant.

It could also be the case that the magnitude or size of the shock will affect whether the response of volatility to shocks is symmetric or not. In this case, a negative size bias test would be conducted, based on a regression where $S_{t-1}^{-}$is used as a slope dummy variable. Negative size bias is argued to be present if $\phi_{1}$ is statistically significant in the following regression:

$$
\hat{z}_{t}^{2}=\phi_{0}+\phi_{1} S_{t-1}^{-} z_{t-1}+\nu_{t}
$$


Finally, we define $S_{t-1}^{+}=1-S_{t-1}^{-}$, so that $S_{t-1}^{+}$picks out the observations with positive innovations. Engle and $\mathrm{Ng}$ (1993) propose a joint test for sign and size bias based on the following regression:

$$
\hat{z}_{t}^{2}=\phi_{0}+\phi_{1} S_{t-1}^{-}+\phi_{2} S_{t-1}^{-} z_{t-1}+\phi_{3} S_{t-1}^{+} z_{t-1}+\nu_{t}
$$

Significance of $\phi_{1}$ indicates the presence of sign bias, where positive and negative shocks have differing impacts upon future volatility, compared with the symmetric response required by the standard GARCH formulation. However, the significance of $\phi_{2}$ or $\phi_{3}$ would suggest the presence of size bias, where not only the sign but the magnitude of the shock is important. A joint test statistic is formulated in the standard fashion by calculating $T R^{2}$ from regression (10), which will asymptotically follow a $\chi^{2}$ distribution with 3 degrees of freedom under the null hypothesis of no asymmetric effects.

Table 2 reports the results of Engle-Ng tests. First, in the whole period, the individual regression results show that the residuals of the symmetric GARCH model for the RGOLD and RSPX series do not suffer from negative size bias and exhibit sign and positive size bias. Second, for the RCMBI and RUSDI series, the individual regression results show that the residuals of the symmetric GARCH model exhibit negative size bias and do not suffer from sign positive size bias. Finally, the $\chi^{2}(3)$ joint test statistics for GOLD, SPX, CMBI, and USDI have $p$ values of $0.0262,0.0000,0.0836$, and 0.0296 , respectively, demonstrating a very rejection of the null of no asymmetries. The results overall would thus suggest motivation for estimating an asymmetric volatility model for these particular series.

In the subsample one, the individual regression results show that the residuals of the symmetric GARCH model for the RGOLD and RSPX series do not suffer from sign and negative size bias and exhibit positive size bias. For the RCMBI, the individual regression results show that the residuals of the symmetric GARCH model exhibit sign bias and do not suffer from negative and positive size bias. For the RUSDI, the individual regression results show that the residuals of the symmetric GARCH model do not suffer from sign, negative and positive size bias.

In the subsample two, the individual regression results show that the residuals of the symmetric GARCH model for the RGOLD and RSPX series do not suffer from positive size bias and exhibit sign and negative size bias. For the RCMBI, the individual regression results show that the residuals of the symmetric GARCH model exhibit positive size bias and do not suffer from sign and negative size bias. For the RUSDI, the individual regression results show that the residuals of the symmetric GARCH model do not suffer from sign and positive size bias and exhibit negative size bias.

Finally, in the subsample three, the individual regression results show that the residuals of the symmetric GARCH model for the RGOLD and RSPX series do not suffer from negative and positive size bias and exhibit sign bias. For the RCMBI and RUSDI, the individual regression results show that the residuals of the symmetric GARCH model exhibit negative size bias and do not suffer from sign and positive size bias. 


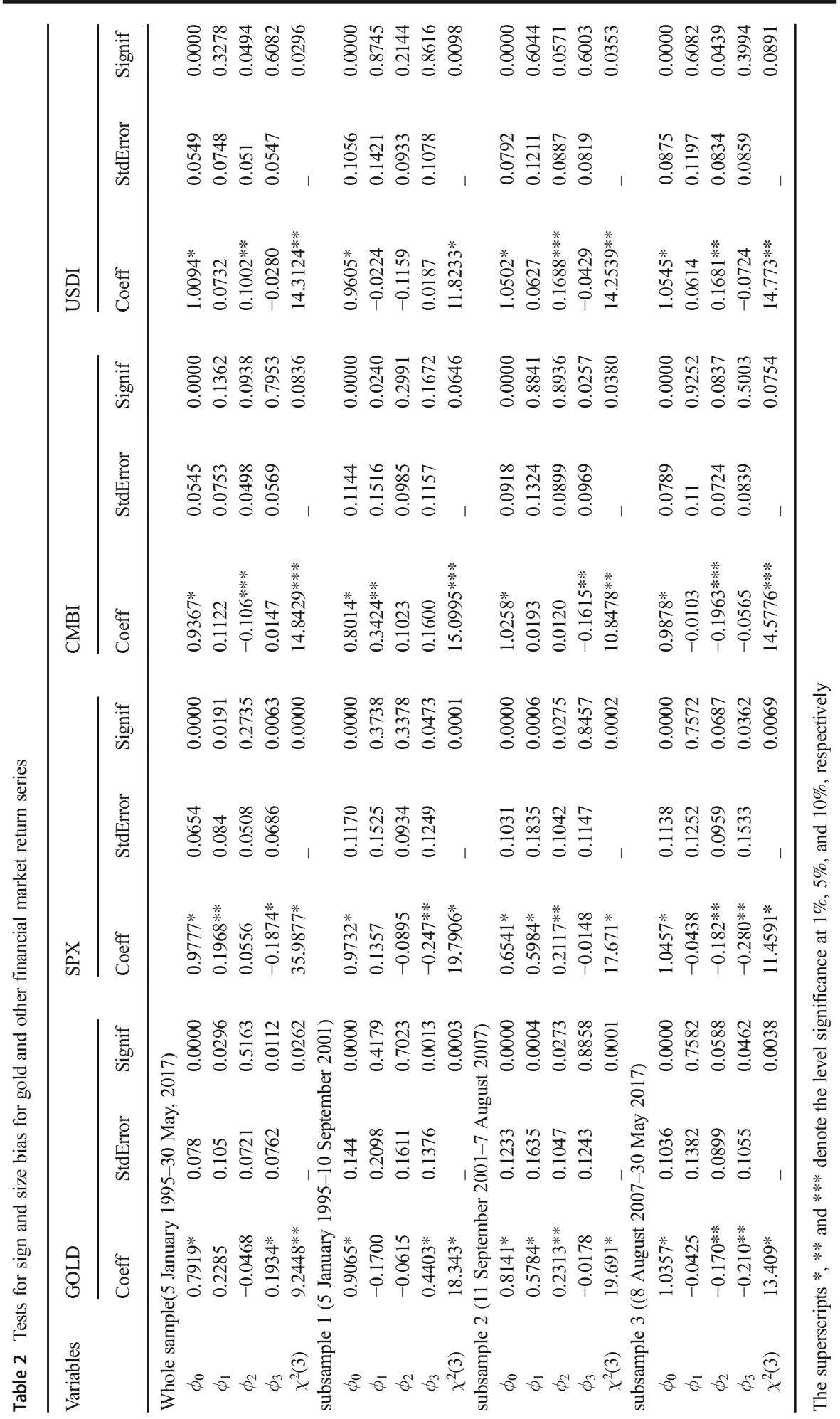




\section{Empirical results}

\subsection{AR-EGARCH specification}

The first step of this specification is to estimate the univariate $A R(m)-E G A R C H(p, q)$ models for each gold and financial market return series. ${ }^{2}$ Table 3 reports the estimates for the $A R(m)-\operatorname{EGARCH}(p, q)$ model. The $\operatorname{EGARCH}(1,1)$ model is chosen for all returns. All the parameters of the EGARCH model are statistically significant at the $1 \%$ significance level or better for all variables in different period of crises. Table 3 also reports the estimates of the parameter $\beta$, which measures the degree of volatility persistence. In the whole period, we find that $\beta$ for GOLD, SPX, CMBI and USDI returns is $0.9953,0.9867,0.9923$ and 0.9953 , respectively. In the subsample 1 , we find that $\beta$ for GOLD, SPX, CMBI and USDI returns is $0.9792,0.9786,0.9761$ and 0.9887 , respectively. In the subsample 2 , we find that $\beta$ for GOLD, SPX, CMBI and USDI returns is $0.9948,0.9922,0.9958$ and 1.0010 , respectively.

Finally, in the subsample 3, we find that $\beta$ for GOLD, SPX, CMBI and USDI returns is $0.9949,0.9900,0.9944$ and 0.9970 , respectively. From these estimates, we could infer that the persistence in shocks to volatility is relatively large.

Table 3 also depicts the diagnostics of the empirical findings of the AR - EGARCH model. $\mathrm{LB}-\mathrm{Q}(20)$ and $\mathrm{LB}-\mathrm{Q}^{2}(20)$ are the Ljung-Box test statistics for the null hypothesis that there is no serial correlation up to order 20 for standardized and squared standardized residuals, respectively. As shown in the table, both statistics are not above $1 \%, 5 \%$ and $10 \%$ in all cases. The null hypothesis of no autocorrelation up to order 20 for squared standardized residuals is accepted.

\subsection{Asymmetric DCC results}

To assess our empirical results and gain further insight into the dynamic correlation structure of gold and other financial markets, we use the Asymmetric Dynamic Conditional Correlation (A-DCC) model developed by Cappiello et al. (2006) in a bivariate framework. Following a first stage approach similar to the DCC model (see Engle (2002)), the univariate EGARCH standardized residuals are used as inputs into the A-DCC estimation process. The estimated parameters $a_{1}$ and $b_{1}$ in the DCC model capture the effects of lagged standardized shocks, $Z_{t-1} Z_{t-1}^{\prime}$, and lagged dynamic conditional correlations, $Q_{t-1}$, on current dynamic conditional correlations, respectively.

The statistical significance of these correlations in each gold price and financial market pair indicates the presence of dynamic correlations. The evaluation of asymmetric correlation responses to negative stock returns is inspected through the parameter $\mathrm{g}_{1}$. The A-DCC model nests the standard DCC model when the parameter $\mathrm{g}_{1}$ is set to equal to zero.

The second step is to estimate the A-DCC model. We use this methodology to test the correlation among the selected returns. Therefore, the outcome views the relationship between the gold price and the other financial markets. Moreover, the subperiods

\footnotetext{
${ }^{2}$ Prior to estimating the univariate $\operatorname{AR}(\mathrm{m})-\operatorname{EGARCH}(\mathrm{p}, \mathrm{q})$ models, we verify that the null hypothesis of stationarity in the return series of gold prices and financial market could not be rejected using the KPSS test.
} 


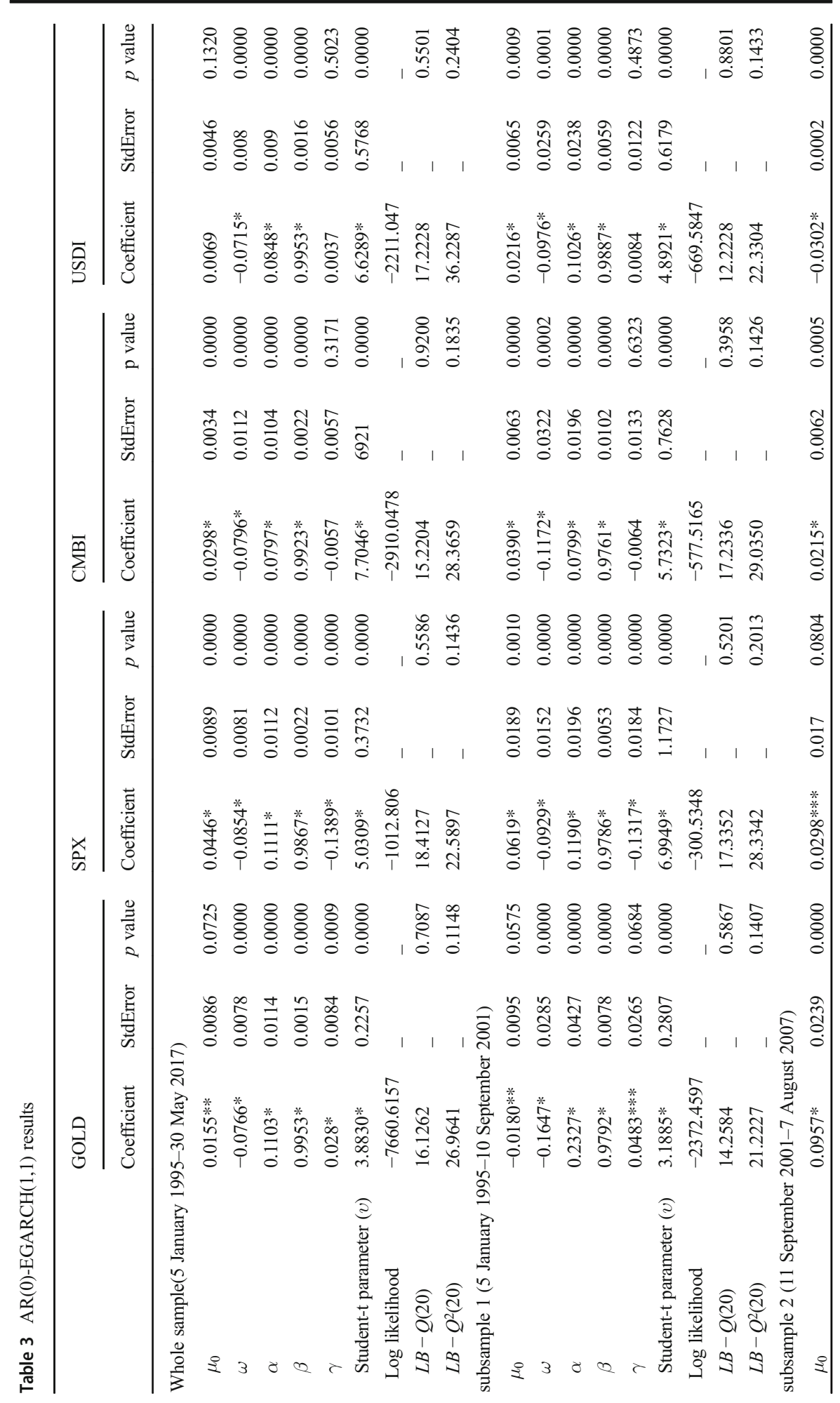




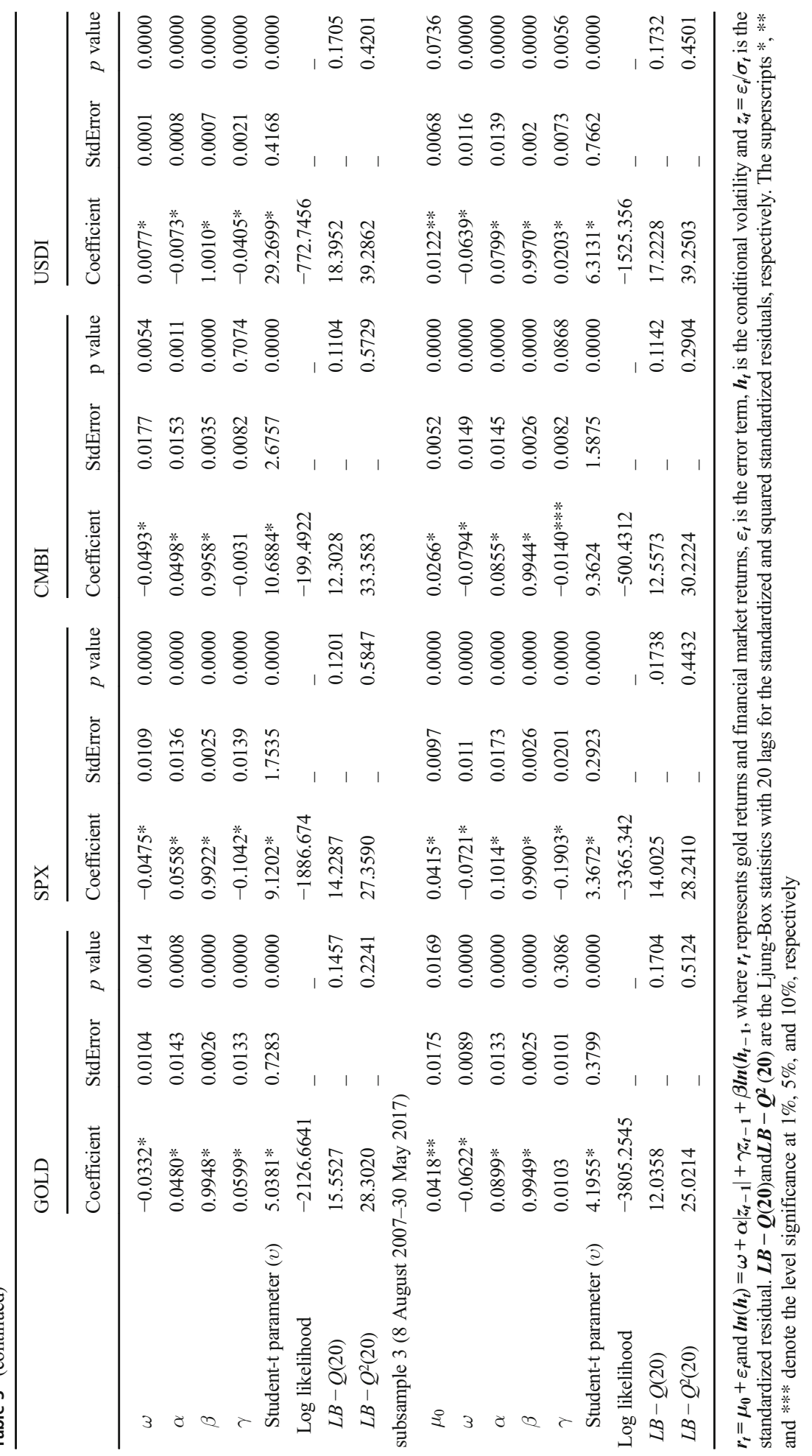


help us to obtain the required findings. Table 4 reports the empirical results for the whole sample period and the three subsample periods. The estimate on the parameter of standardized residuals $\left(a_{1}\right)$ is statistically significant at the $1 \%$ level. The parameter of innovation in the dynamics of the conditional correlation matrix $\left(b_{1}\right)$ is statistically significant at the $1 \%$ level for all return series. Moreover, the estimate on the parameter of the asymmetry term $\left(\mathrm{g}_{1}\right)$ is only significant. Table 4 shows the empirical findings by subperiod. First, we show that the estimate on the parameter of the asymmetry term $\left(g_{1}\right)$ is statistically significant for gold and financial market returns for all subperiods. Second, we find that while the $\mathrm{g}_{1}$ coefficient for samples 1,2 and 3 is statistically significant at conventional levels, it is positive and statistically significant at the $1 \%$

Table 4 Asymmetric DCC results (Whole sample and subsample analysis)

\begin{tabular}{|c|c|c|c|c|c|c|}
\hline & \multicolumn{3}{|c|}{ Symmetric DCC } & \multicolumn{3}{|c|}{ Asymmetric DCC } \\
\hline & coefficient & Std.Error & $p$ value & coefficient & Std.Error & $p$ value \\
\hline \multicolumn{7}{|c|}{ Whole sample(5 January 1995-30 May 2017) } \\
\hline$a_{1}$ & $0.1277^{*}$ & 0.0047 & 0.0000 & $0.1277^{*}$ & 0.0046 & 0.0000 \\
\hline$b_{1}$ & $0.9897 *$ & 0.0008 & 0.0000 & $0.9897 *$ & 0.0008 & 0.0000 \\
\hline$g_{1}$ & _- & _- & _- & $0.1235^{*}$ & 0.0031 & 0.0003 \\
\hline Log likelihood & $-18,919.0079$ & _- & _- & $-18,919.0079$ & - & _ \\
\hline $\mathrm{BIC}$ & $38,063.61595$ & - & _- & $38,072.29288$ & - & _- \\
\hline \multicolumn{7}{|c|}{ subsample 1 (5 January 1995-10 September 2001) } \\
\hline$a_{1}$ & $0.1236^{*}$ & 0.0101 & 0.0000 & $0.1236^{*}$ & 0.0108 & 0.0000 \\
\hline$b_{1}$ & $0.9884^{*}$ & 0.0023 & 0.0000 & $0.9884^{*}$ & 0.0023 & 0.0000 \\
\hline$g_{1}$ & - & - & - & $0.1722 *$ & 0.0048 & 0.0001 \\
\hline Log likelihood & -5013.2033 & _ & _- & -5013.2033 & - & - \\
\hline $\mathrm{BIC}$ & $10,220.43914$ & _- & _- & $10,227.90192$ & - & _- \\
\hline \multicolumn{7}{|c|}{ subsample 2 (11 September 2001-7 August 2007) } \\
\hline$a_{1}$ & $0.1263^{*}$ & 0.0097 & 0.0000 & $0.0021^{*}$ & 0.0101 & 0.0000 \\
\hline$b_{1}$ & $0.9883^{*}$ & 0.0021 & 0.0000 & $0.9883^{*}$ & 0.0021 & 0.0000 \\
\hline$g_{1}$ & _- & - & _- & $0.1428^{*}$ & 0.0149 & 0.0004 \\
\hline Log likelihood & -4714.582 & _- & _- & -4714.582 & - & - \\
\hline $\mathrm{BIC}$ & 9619.9919 & _ & _- & 9627.3314 & - & _- \\
\hline \multicolumn{7}{|c|}{ subsample 3 ((8 August 2007-30 May 2017) } \\
\hline$a_{1}$ & $0.1394 *$ & 0.0082 & 0.0000 & $0.1394 *$ & 0.0078 & 0.0000 \\
\hline$b_{1}$ & $0.9867 *$ & 0.0019 & 0.0000 & $0.9867 *$ & 0.0018 & 0.0000 \\
\hline$g_{1}$ & _- & _- & - & $0.2156^{*}$ & 0.0228 & 0.0000 \\
\hline Log likelihood & -9062.2241 & - & _ & -9062.2241 & - & - \\
\hline BIC & $18,328.7124$ & _- & _- & $18,336.5687$ & - & - \\
\hline
\end{tabular}

$Q_{t}=\left(1-a_{1}-b_{1}\right) \bar{Q}-g_{1} \bar{N}+a_{1} Z_{t-1} Z_{t-1}^{\prime}+b_{1} Q_{t-1}+g_{1} \eta_{t-1} \eta_{t-1}^{\prime}$ where $Q_{t}$ is the conditional covariance matrix between the standardized residuals; $\boldsymbol{Z}_{t}$ is the matrix of the standardized residuals; $\overline{\boldsymbol{Q}}$ and $\overline{\boldsymbol{N}}$ are the unconditional correlation matrices of $\boldsymbol{Z}_{i}, \boldsymbol{\eta}_{t}=\boldsymbol{I}\left[\boldsymbol{Z}_{\boldsymbol{t}}<\mathbf{0}\right] \cdot \boldsymbol{Z}_{\boldsymbol{t}}$ and $\boldsymbol{I}\left[\right.$.] is a $\boldsymbol{k} \times \mathbf{1}$ indicator function such as $\boldsymbol{I}=\mathbf{1}$ if $\boldsymbol{Z}_{\boldsymbol{t}}<\mathbf{0}$ and $\boldsymbol{I}=\mathbf{0}$ if $\boldsymbol{Z}_{\boldsymbol{t}} \geq \mathbf{0}$, while " $\bullet "$ is the Hadamard product. The superscripts *, ** and *** denote the level significance at $10 \%, 5 \%$ and $1 \%$, respectively 
level for the three subsample. This result suggests that the interdependent relationship between gold and financial market has grown during the different period of crises.

Figures 1, 2, 3 and 4 plots the estimated DCCs between each pair of the gold and financial market prices. First, the time path of the DCC series fluctuates over the sample period for all pairs, thereby suggesting that the assumption of constant correlations may not be appropriate. This result is generally in line with empirical studies such as PerezRodriguez (2006) and Tamakoshi and Hamori (2014). Second, Figures shows that the correlation decreases numerically if a large negative shock hits the gold and U.S. dollar markets simultaneously. Therefore, to some extent, gold plays a role in hedging against depreciation of the U.S. dollar. Generally, gold price increases in response to decreases in the U.S. dollar because investors demand gold to store value or to compensate for losses, and vice versa. This inverse correlation has already been pointed out in many previous studies (e.g. Hammoudeh et al. 2009; Bhar and Hammoudeh 2011).

\section{Conclusion}

While time varying correlations of gold price and financial market have seen voluminous research, relatively little attention has been given to the dynamics of correlations within a market.

In this paper, we analyze the dynamic conditional correlation between three financial market namely SPX, CMBI and USDI and gold price using the Asymmetric Dynamic Conditional Correlation (A-DCC) model developed by Cappiello et al. (2006). We also use an AR-EGARCH model for statistical analysis of the time-varying correlations by considering the major financial and economic events relative to the terrorist attacks, the
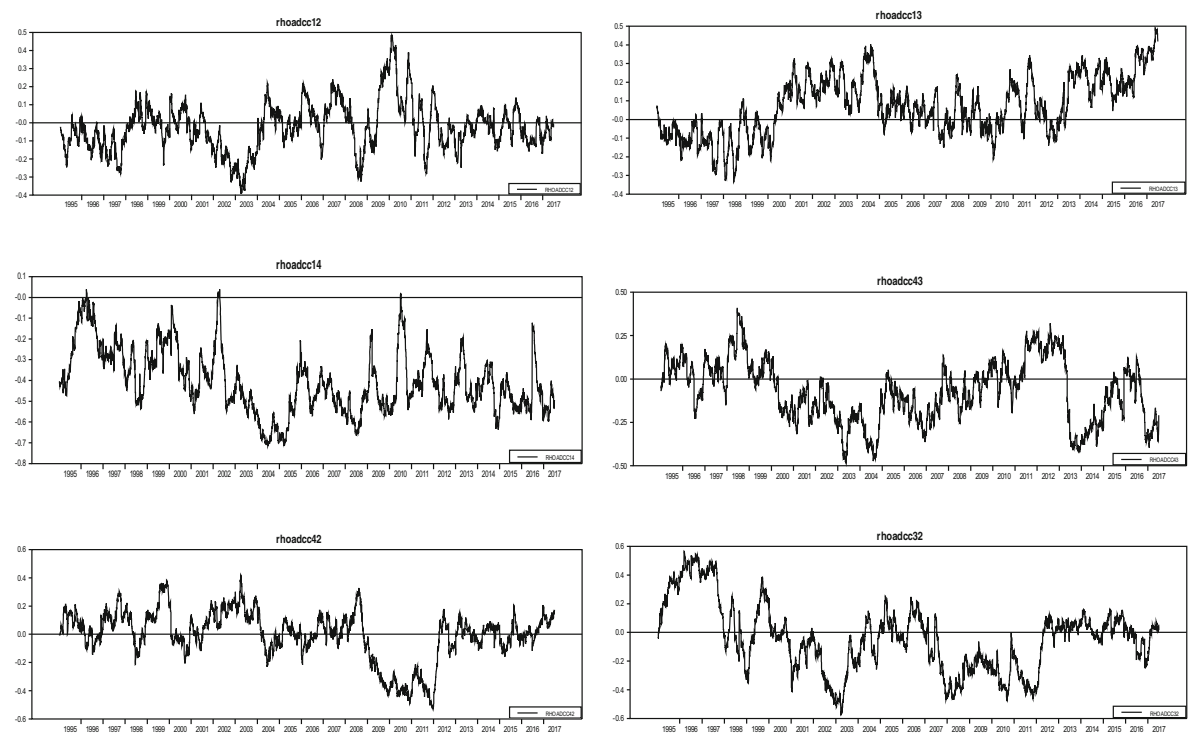

Fig. 1 Dynamic conditional correlations between each gold price and financial market pair. (a) The DCC between the GOLD and SPX. (b) The DCC between the GOLD and CMBI. (c) The DCC between the GOLD and USDI. (d) The DCC between the USDI and CMBI. (e) The DCC between the USDI and SPX. (e) The DCC between the CMBI and SPX. (Whole sample: January 5, 1995, to May 30, 2017) 

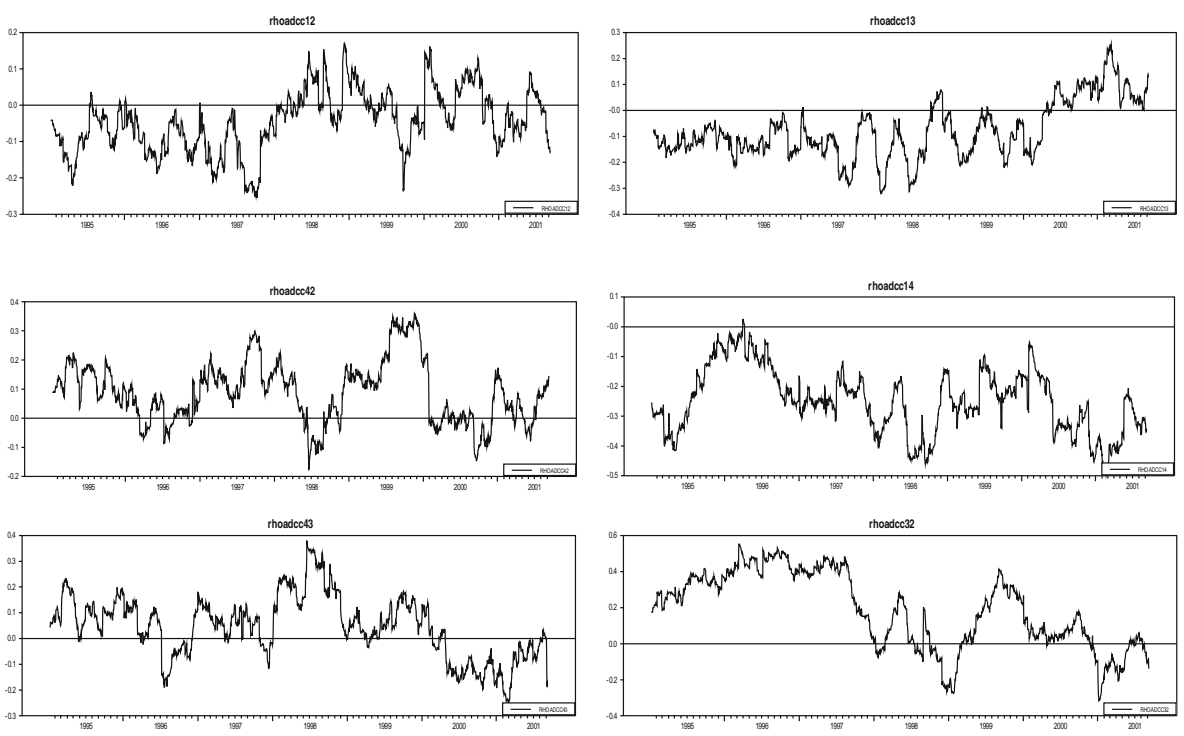

Fig. 2 Dynamic conditional correlations between each gold price and financial market pair. (a) The DCC between the GOLD and SPX. (b) The DCC between the GOLD and CMBI. (c) The DCC between the GOLD and USDI. (d) The DCC between the USDI and CMBI. (e) The DCC between the USDI and SPX. (e) The DCC between the CMBI and SPX. (Subsample 1: January 5, 1995, to September 10, 2001)

subprime mortgage turmoil and the global financial crisis. The A-DCC model allows for conditional asymmetries in covariance and correlation dynamics, thereby enabling to examine the presence of asymmetric responses in correlations during periods of negative shocks. We then extended the above univariate GARCH models to a bivariate
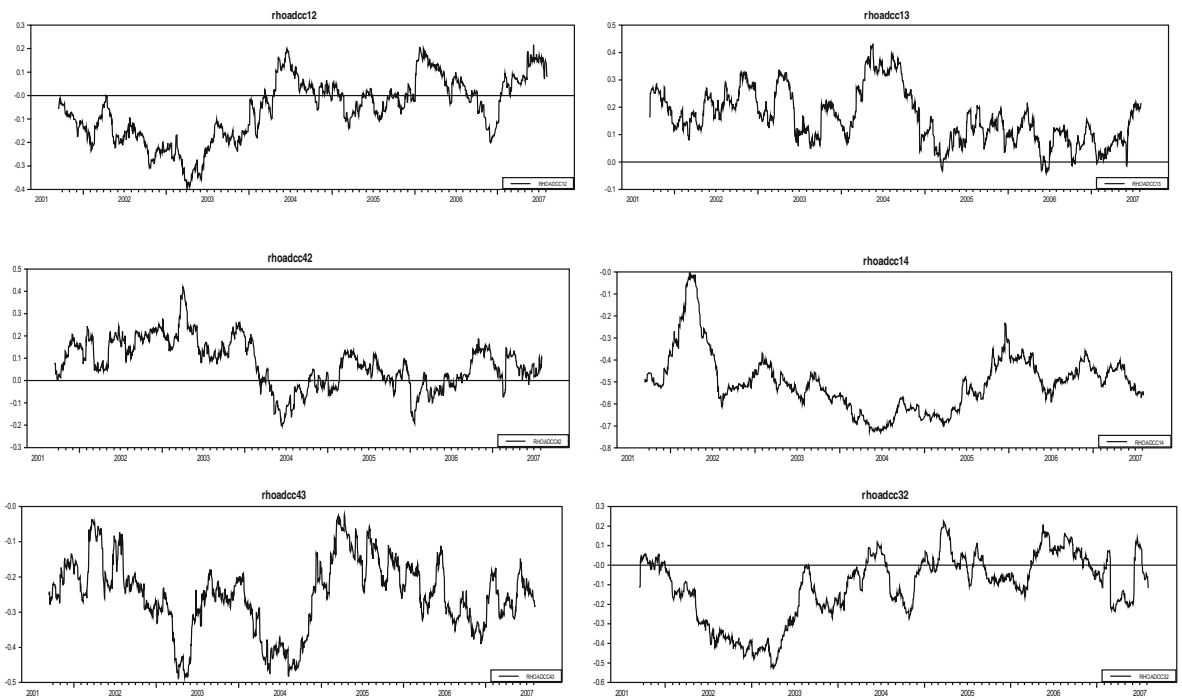

Fig. 3 Dynamic conditional correlations between each gold price and financial market pair. (a) The DCC between the GOLD and SPX. (b) The DCC between the GOLD and CMBI. (c) The DCC between the GOLD and USDI. (d) The DCC between the USDI and CMBI. (e) The DCC between the USDI and SPX. (e) The DCC between the CMBI and SPX. (Subsample 2: September 11, 2001, to Aout 7, 2007) 

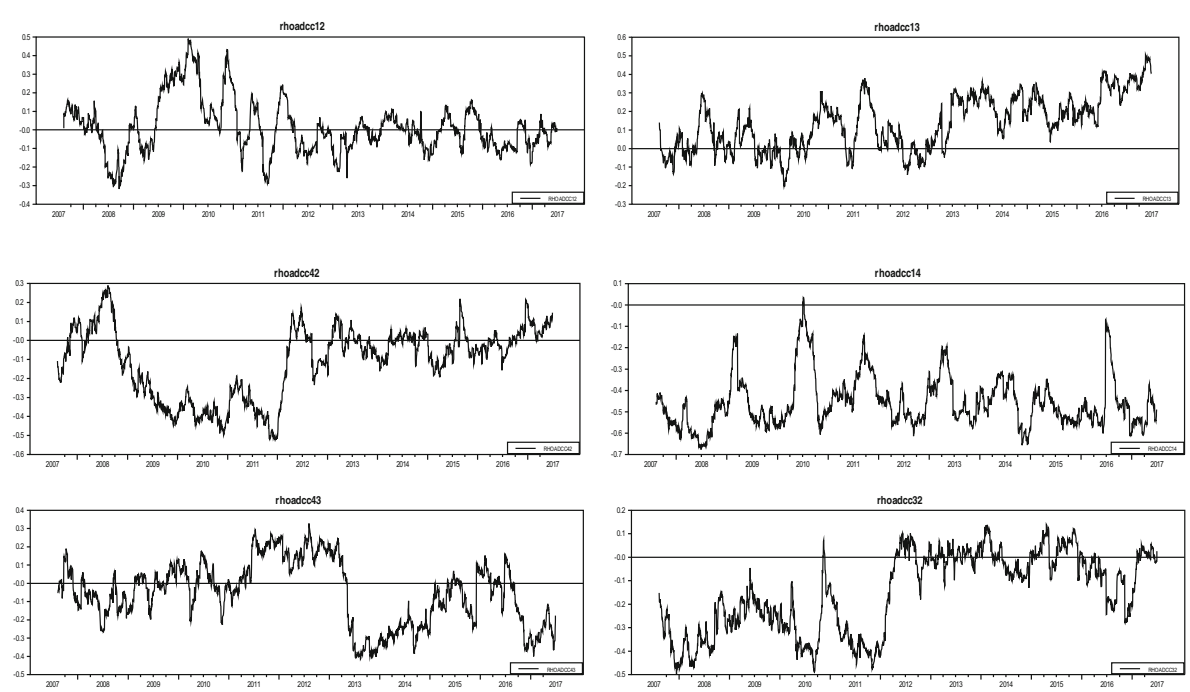

Fig. 4 Dynamic conditional correlations between each gold price and financial market pair. (a) The DCC between the GOLD and SPX. (b) The DCC between the GOLD and CMBI. (c) The DCC between the GOLD and USDI. (d) The DCC between the USDI and CMBI. (e) The DCC between the USDI and SPX. (e) The DCC between the CMBI and SPX. (Subsample 3: Aout 8, 2007, to May 30, 2017)

framework with dynamic conditional correlation parameterization in order to investigate the interaction between gold price and other financial markets.

Our empirical results indicate that gold and financial market exhibit asymmetry in the conditional variances. Therefore, the results point to the importance of applying an appropriately flexible modeling framework to accurately evaluate the interaction between gold price and financial market co-movements. The conditional correlation among the gold and the three financial market exhibits higher dependency when it is driven by negative innovations to changes than it is by positive innovations. we find that correlations display substantial time variation for all pairs even when similar market conditions emerge. Our findings suggest that investors should take into consideration the asymmetric dependence structure, which depends on the upside or downside of the market, to control risk exposure reasonably.

Our empirical findings seem to be important to researchers and practitioners and especially to active investors and portfolio managers who include in their portfolios equities from the gold and other financial markets. The findings lead to important implications from investors' and policy makers' perspective. They are of great relevance for financial decisions of international investors on managing their risk exposures to gold price and financial market fluctuations and on taking advantages of potential diversification opportunities that may arise due to lowered dependence among financial market and gold. The increase of gold and other financial market linkages during crisis periods implies a decrease of portfolio diversification benefits, since holding a portfolio with diverse currencies is less subject to systematic risk. Moreover, this correlations' behavior may be considered as evidence of non-cooperative monetary policies around the world and highlight the need for some form of policy coordination among central banks. Finally, the different patterns of dynamic linkages among gold price and other financial market may influence transnational trade flows and the activities of multinational corporations, as they create uncertainty with regard to exports and imports. 
Acknowledgements The authors are grateful to an anonymous referees and the editor for many helpful comments and suggestions. Any errors or omissions are, however, our own.

Open Access This article is distributed under the terms of the Creative Commons Attribution 4.0 International License (http://creativecommons.org/licenses/by/4.0/), which permits unrestricted use, distribution, and reproduction in any medium, provided you give appropriate credit to the original author(s) and the source, provide a link to the Creative Commons license, and indicate if changes were made.

\section{References}

Ang A, Bekaert G (2002) International asset allocation with regime shifts. Rev Financ Stud 15:1137-1187. https://doi.org/10.1093/rfs/15.4.1137

Ang A, Chen J (2002) Asymmetric correlations of equity portfolios. J Financ Econ 63:443-494. https://doi. org/10.1016/S0304-405X(02)00068-5

Arouri MEH, Lahiani A, Nguyen DK (2015) World gold prices and stock returns in China: insights for hedging and diversification strategies. Econ Model 44:273-282

Baur DG (2011) Explanatory Mining for Gold: contrasting evidence from simple and multiple regressions. Resources Policy 36:265-275. https://doi.org/10.1016/j.resourpol.2011.03.003

Baur DG, Lucey BM (2010) Is gold a hedge or a safe haven? An analysis of stocks, bonds and gold. Financ Rev 45:217-229. https://doi.org/10.1111/(ISSN)1540-6288

Baur DG, McDermott TK (2010) Is gold a safe haven? International evidence. J Bank Financ 34:1886-1898. https://doi.org/10.1016/j.jbankfin.2009.12.008

Bekiros S, Boubaker S, Nguyen DK, Uddin GS (2017) Black swan events and safe havens: the role of gold in globally integrated emerging markets. J Int Money Fin 73:317-334. https://doi.org/10.1016/j. jimonfin.2017.02.010

Bhar R, Hammoudeh S (2011) Commodities and financial variables : analyzing relationship in a changing regime environment. Int Rev Econ Financ 20:469-484

Bollerslev T (1987) A conditionally heteroskedastic time series model for speculative prices and rates of return. Rev Econ Stat 69:542-547

Bouri E, Jain A, Biswal PC, Roubaud D (2017a) Cointegration and nonlinear causality amongst gold, oil, and the Indian stock market: evidence from implied volatility indices. Resources Policy 52:201-206

Bouri E, Roubaud D, Jammazi R, Assaf A (2017b) Uncovering frequency domain causality between gold and the stock markets of China and India: evidence from implied volatility indices. Financ Res Lett 23:23-30

Campbell RA, Forbes CS, Koedijk KG, Kofman P (2008) Increasing correlations or just fat tails? J Empir Financ 15:287-309. https://doi.org/10.1016/j.jempfin.2007.01.001

Cappiello L, Engle R, Sheppard K (2006) Asymmetric dynamics in the correlations of global equity and bond returns. J Financ Econ 4(4):537-572

Domanski D, Heath A (2007) Financial investors and commodity markets. BIS Quarterly Review 3:53-67

Engle RF (2002) Dynamic conditional correlation: a simple class of multivariate generalized autoregressive conditional heteroskedasticity models. J Bus Econ Stat 20(3):339-350

Engle RF, Ng VK (1993) Measuring and testing the impact of news on volatility. J Financ 48(5):1749-1778

Gurgun G, Unalmis I (2014) Is gold a safe haven against equity market investment in emerging and developing countries. Financ Res Lett 11:341-348. https://doi.org/10.1016/j.frl.2014.07.003

Hammoudeh S, Sari R, Ewing B (2009) Relationships among strategic commodities and with financial variables: a new look. Contemp Econ Policy 27:251-269

Hillier D, Draper P, Faff R (2006) Do precious metals Shine? An investment perspective. Financ Anal J 62: 98-106. https://doi.org/10.2469/faj.v62.n2.4085

Hood M, Malik F (2013) Is gold the best hedge and a safe haven under changing stock market volatility? Rev Financ Econ 22:47-52. https://doi.org/10.1016/j.rfe.2013.03.001

Jain A, Biswal PC (2016) Dynamic linkages among oil price, gold price, exchange rate, and stock market in India. Resour Policy 49:179-185. https://doi.org/10.1016/j.resourpol.2016.06.001

Kang SH, McIver R, Yoon SM (2016) Modeling time-varying correlations in volatility between BRICS and commodity markets. Emerg Mark Financ Trade 52(7):1698-1723

Kenourgios D, Samitas A, Paltalidis N (2011) Financial crises and stock market contagion ina multivariate time-varying asymmetric framework. J. Int. Financ. Mark. Inst. Money 21:92-106 
Kumar D (2014) Return and volatility transmission between gold and stock sectors: application of portfolio management and hedging effectiveness. IIMB Manage Rev 26:5-16. https://doi.org/10.1016/j. iimb.2013.12.002

Longin F, Solnik B (2001) Extreme correlation of international equity markets. J Financ 56:649-676. https://doi.org/10.1111/jofi.2001.56.issue-2

Mensi W, Hammoudeh S, Reboredo JC, Nguyen DK (2014) Do global factors impact BRICS stock markets? A quantile regression approach. Emerg Mark Rev 19:1-17

Miyazaki T, Hamori S (2013) Testing for causality between the gold return and stock market performance: evidence for 'gold investment in case of emergency. Appl Financ Econ 23:27-40. https://doi.org/10.1080 /09603107.2012.699184

Miyazaki T, Hamori S (2014) Cointegration with regime shift between gold and financial variables. International Journal of Financial Research 5:90-97. https://doi.org/10.5430/ijfr.v5n4p90

Nelson DB (1991) Conditional heteroskedasticity in asset returns: a new approach. Econometrica 59:347-370

Perez-Rodriguez JV (2006) The euro and other major currencies floating against the US dollar. Atl Econ J 34: 367-384

Qadan M, Yagil J (2012) Fear sentiments and gold Price: testing causality in-mean and in-variance. Appl Econ Lett 19:363-366. https://doi.org/10.1080/13504851.2011.579053

Raza N, Shahzad SJH, Tiwari AK, Shahbaz M (2016) Asymmetric impact of gold, oil prices and their volatilities on stock prices of emerging markets. Resour Policy 49:290-301

Samitas A, Tsakalos I (2013) How can a small country affect the European economy? The Greek contagion phenomenon. J Int Financ Mark Inst Money 25:18-32

Sarwar G (2017) Examining the flight-to-safety with the implied volatilities. Fin Res Lett 20:118-124. https://doi.org/10.1016/j.frl.2016.09.015

Sarwar G, Khan W (2017) The effect of US stock market uncertainty on emerging market returns. Emerg Mark Financ Trade 53(8):1796-1811

Silvennoinen A, Thorp S (2013) Financialization, crisis and commodity correlation dynamics. J. Int. Financ. Mark. Inst. Money 24:42-65. https://doi.org/10.1016/j.intfin.2012.11.007

Tamakoshi G, Hamori S (2014) Co-movements among major European exchange rates: A multivariate timevarying asymmetric approach. Int Rev Econ Financ, 31:105-113

Tang K, Xiong W (2012) Index investment and the Financialization of commodities. Financ Anal J 68:54-74. https://doi.org/10.2469/faj.v68.n6.5

Toyoshima Y, Hamori S (2013) Asymmetric dynamics in stock market correlations: evidence from Japan and Singapore. J Asian Econ 24:117-123

Toyoshima Y, Tamakoshi G, Hamori S (2012) Asymmetric dynamics in correlations of treasury and swap markets: evidence from the US market. J Int Financ Mark Inst Money 22:381-394

Wang ML, Wang CP, Huang TY (2010) Relationships among oil price, gold price, exchange rate and international stock markets. Int Res J Fin Econ 47:82-91

$\mathrm{Xu}$ H, Hamori S (2012) Dynamic linkages of stock prices between the BRICs and the United States: effects of the 2008-09 financial crisis. J Asian Econ 23(4):344-352

Yang Z, Zhou Y (2017) Quantitative easing and volatility spillovers across countries an asset classes. Manag Sci 63(2):333-354

Publisher's note Springer Nature remains neutral with regard to jurisdictional claims in published maps and institutional affiliations. 